
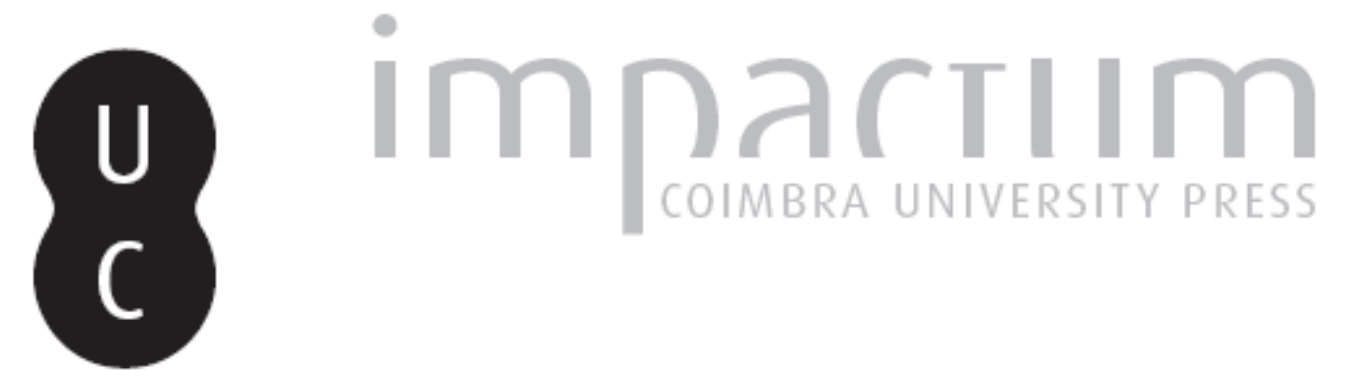

\title{
Tiglat-Pileser I à luz do debate sobre a nova cronologia para a história do próximo Oriente Antigo
}

Autor(es): $\quad$ Palma, Maria de Lurdes

Publicado por: Centro de História da Universidade de Lisboa

URL persistente:

URI:http://hdl.handle.net/10316.2/23782

DOI:

DOI:http://dx.doi.org/10.14195/0871-9527_19_6

Accessed : $\quad$ 26-Apr-2023 14:29:00

A navegação consulta e descarregamento dos títulos inseridos nas Bibliotecas Digitais UC Digitalis, UC Pombalina e UC Impactum, pressupõem a aceitação plena e sem reservas dos Termos e Condições de Uso destas Bibliotecas Digitais, disponíveis em https://digitalis.uc.pt/pt-pt/termos.

Conforme exposto nos referidos Termos e Condições de Uso, o descarregamento de títulos de acesso restrito requer uma licença válida de autorização devendo o utilizador aceder ao(s) documento(s) a partir de um endereço de IP da instituição detentora da supramencionada licença.

Ao utilizador é apenas permitido o descarregamento para uso pessoal, pelo que o emprego do(s) título(s) descarregado(s) para outro fim, designadamente comercial, carece de autorização do respetivo autor ou editor da obra.

Na medida em que todas as obras da UC Digitalis se encontram protegidas pelo Código do Direito de Autor e Direitos Conexos e demais legislação aplicável, toda a cópia, parcial ou total, deste documento, nos casos em que é legalmente admitida, deverá conter ou fazer-se acompanhar por este aviso.

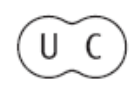



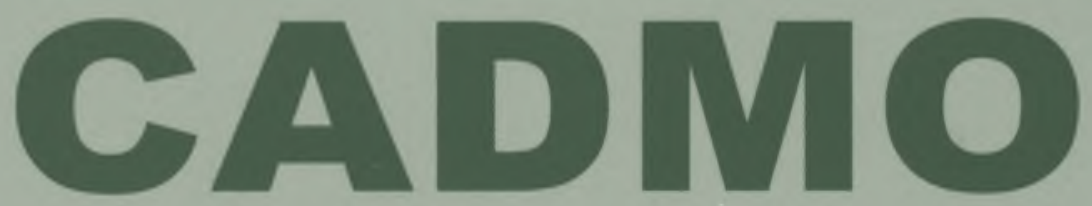

Revista de História Antiga

\author{
Centro de História \\ da Universidade de Lisboa
}

19

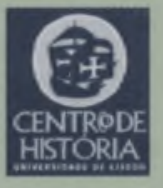

430 =

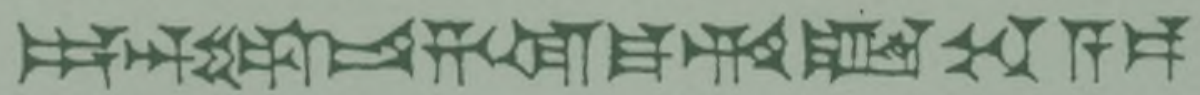

MHNIN AEI $\Delta$ E $\Theta E A ~ \Pi H \Lambda H I A \triangle E \Omega$ 


\title{
TIGLAT-PILESER I À LUZ DO DEBATE SOBRE A NOVA CRONOLOGIA PARA A HISTÓRIA DO PRÓXIMO ORIENTE ANTIGO
}

\author{
MARIA DE LURDES PALMA \\ Universidade de Lisboa \\ mlpalma@sapo.pt
}

\section{Resumo}

A chamada "nova cronologia" suprime o "período obscuro" (Dark Ages) reduzindo em cerca de duzentos anos a cronologia do mundo antigo. Tiglat-pileser I governou, assim, entre 1031-992 a. C. e terá contribuído para o colapso final do Império Hitita.

Palavras-chave: Tiglat-pileser I; nova cronologia; Império Hitita.

\begin{abstract}
The new chronology suppresses the Dark Ages reducing by around 200 years the chronology of the Ancient World. Tiglath-pileser I ruled between 1031-992 BC and so may have contributed to the final collapse of the Hittite Empire.
\end{abstract}

Key-Words: Tiglath-pileser I; new chronology; Hittite Empire. 


\section{Uma nova cronologia para o Próximo Oriente antigo?}

Sendo a cronologia trave mestra da história (ciência do passado humano inscrito no tempo), cuja essência nos permite estabelecer nexos de compreensão e explicação dos dados históricos, é particularmente importante no que concerne à história política. Sem a sequência temporal, a História perde densidade, consistência, e afunda-se num conjunto de «informações» desprovido de significado para o entendimento do percurso humano. Os métodos de datação revelam-se, assim, como instrumentos preciosos para a interpretação dos «testemunhos" da história humana, porquanto a memória histórica se alicerça no encadeamento de referências temporais. Se para a história mais recente, ou seja, desde c. 700 a. C. até à actualidade, os historiadores podem dispor de uma cronologia absoluta credível, já para a história do Próximo Oriente antigo, dos início do III milénio ao I milénio a. C., aos especialistas são oferecidos cenários distintos quanto à consistência da inscrição temporal dos acontecimentos registados, sobretudo em fontes textuais, e uma cronologia absoluta sem reservas não tem sido possível. Foi neste contexto, aliás, que os historiadores criaram uma cronologia longa, média ou curta e, não será por acaso, que a prefencial seja a média.

A cronologia que envolve a história antiga (Próximo Oriente e mundo mediterrânico) tem sido alvo, nas duas últimas décadas, de aceso debate. O cepticismo instalado no meio arqueológico face aos quadros cronológicos estabelecidos, particularmente no que respeita ao Próximo Oriente antigo e com especial reserva para um período de longa duração comummente designado por "período obscuro" (Dark Ages, $1200-700$ a. C.), motivou um grupo de estudiosos ingleses a centrarem as suas investigações neste âmbito a partir de 1985 e foi responsável pela publicação, em 1991, da obra Centuries of Darkness( ${ }^{(1)}$, cuja extensão, em temos geográficos, abrange desde o Mediterrâneo Ocidental até ao Irão e, em termos temporais, o período mais crítico da cronologia convencional: 1200-800 a. C. Ainda em 1985 foi fundado The Institute for the Study of Interdisciplinary Sciences (ISIS ${ }^{(2)}$ ), cuja actividade cessou em 2005, e que publicou o Journal of the Ancient Chronology Forum (JACF) entre 1987 e 2006, dez volumes exclusivamente dedicados à pesquisa (com suporte arqueológico e textual) sobre as grandes culturas do Mediterrâneo e Próximo Oriente antigos, com vista à definição de uma nova cronologia. Em 1987 ocorreu na Suécia um colóquio internacional debruçado inteiramente à cro- 
nologia para o mundo antigo ${ }^{(3)}$; em 1990 a revista $B A S O R$ dedicou a esta temática o seu número de Primavera ${ }^{(4)}$.

A publicação, já referida, da obra Centuries of Darkness contribuiu decisivamente para uma crítica mais sólida face às reservas colocadas perante algumas fontes historiográficas antigas. Brinkman, autoridade académica no que diz respeito à cronologia mesopotâmica, sublinhara, já na década de 70 , a necessidade de uma abordagem mais crítica face à "Lista de Reis" assíria, considerada pelos académicos como a espinha dorsal da cronologia mesopotâmica ${ }^{(5)}$, apesar dos seus erros. Ao ser colocado um nome (de rei) após outro, o poder flui cronologicamente, que o mesmo é dizer, a sucessão de reinados inscreve-se num tempo linear. Porém, na Mesopotâmia, desenvolveu-se em paralelo a ideia de um tempo cíclico que introduzia a mudança ou alteração (mas não a novidade), e que parece ter dominado o pensamento "histórico" quer dos Babilónios quer dos Assírios: o tempo cíclico subordinou o tempo linear. Os deuses governavam o mundo e decidiam do seu favor ou da sua recusa face aos monarcas humanos e a ideia do tempo cíclico (acontecimentos que se repetem), que obedecia a uma lei cósmica harmonizava o registo do "cronista" mesopotâmico no seu desejo de interpelar o passado para explicar o presente. Assim, uma leitura menos "seguidista" das fontes historiográficas antigas (particularmente assírias) poder-nos-á conduzir a uma reconstrução da história mesopotâmica assaz distinta do discurso convencional e colocar novas questões historiográficas.

A obra de P. James (Century of Darkness), saída do mundo da arqueologia, mereceu uma rejeição imediata da parte de N. Postgate, apoiando-se este no sistema de ordenação cronológica a partir do critério eponímico ${ }^{(6)}$. De há vinte anos para cá, todavia, têm-se multiplicado os estudos referentes à cronologia do mundo antigo, sendo apontada uma redução em cerca de duzentos anos, privilegiando-se o cruzamento de dados sutentados pela arqueologia, por fontes textuais e, ainda, por técnicas de datação que incluem o radiocarbono e a dendocronologia. Uma visão de conjunto das civilizações e culturas antigas (Próximo Oriente e Mediterrâneo) e uma exactidão histórica e uma minimização de cronologia dependente de anomalias históricas ou arqueológicas constituiram os critérios norteadores de uma tese de doutoramento apresentada na Universidade de Melbourne em $2007^{(7)}$.

No tocante à história médio-assíria, a cronologia alternativa propõe um quadro de dinastias paralelas, co-regências e ainda a existên- 
cia de reis guerreiros e reis sacerdotes. Newgrosh ${ }^{(8)}$ chamou a atenção para a ausência de inscrições reais (ou muito limitadas) que descrevam actividades militares, trabalhos de construção, documentos jurídicos/económicos ou até mesmo epónimos, relativas a soberanos assírios que constam da "Lista de Reis", particularmente nos tempos conturbados que se seguiram à morte de Tukulti-Ninurta I e Tiglat-pileser I. A sua tese é a de que estes "reis sombra» terão desempenhado um papel diferente daqueles cujas acções conhecemos do registo historiográfico antigo. Assim, os soberanos cuja informação é abundante foram classificados de reis guerreiros, enquanto os outros ("reis sombra») terão desempenhado funções religiosas - reis sacerdotes. Daqui resultaram naturalmente dinastias paralelas. Sublinha o autor que este modelo alternativo de exercício de governação apresenta vantagens - enquanto o rei guerreiro se encontrava nas campanhas militares, logo, afastado da cidade de Aššur, o rei sacerdote cumpria as obrigações religiosas e quando um rei guerreiro morria no decurso de uma campanha militar, então o rei sacerdote assumia a governação até ao anúncio do sucessor do monarca falecido.

Por outro lado, P. James já chamara a atenção para a prática das co-regências, com vista a assegurar a sucessão e a estabilidade do estado, a qual parece ter sido uma prática recorrente no Próximo Oriente antigo ${ }^{(9)}$, assinalando, para o caso assírio, o rei Aššur-dan I (c. 1178-1133 a. C.) e os seus filhos Ninurta-tukulti-Aššur e Mutakkil-Nusku, para cujos reinados não é indicada a duração respectiva, e ainda o tempo entre Aššur-dan I e o seu pai, Ninurta-apil-Ekur (c. 1191-1179 a. C. $)^{(10)}$.

A reflexão que ora se apresenta, centrada no reinado de Tiglat-pileser I, assenta no debate/proposta de cronologia alternativa para o Próximo Oriente antigo e, particularmente, na tese de doutoramento de P. J. Furlong acima mecionada ${ }^{(11)}$.

\section{As listas de reis assírias}

A «Lista de Reis» assíria é um texto cronográfico, assente numa prioridade temporal diacrónica, que nos revela uma sequência de nomes, filiação real, duração de cada reinado e indicação breve de actividade militar. São conhecidos cinco "exemplares", sendo o mais completo composto pelos nomes dos reis assírios desde os tempos mais recuados até Salmanassar V (CC c. 726-722 a. C. $)^{(12)}$. O «exem- 
plar" mais antigo parece enquadrar-se no período a seguir ao reinado de Tiglat-pileser II (CC c. 966-935 a. C.), e o mais completo coincidindo com o mais recente, ou seja, ao tempo de Salmanassar V (CC c. 722 a. C.). Brinkman ${ }^{(13)}$ identificou discrepâncias quanto à duração dos reinados $^{(14)}$ e à genealogia(15), variações em nomes reais ${ }^{(16)}$ e ainda omissões ${ }^{(17)}$, ao comparar os dados provindos dos diferentes "exemplares".

A sua composição deverá remontar, no entanto, ao tempo de Šamši-Adad I tendo sido reescrita sucessivamente(18). S. Yamada identificou 3 momentos de reedição/actualização, para a "Lista de Reis" assíria (= Aššur B), até ao período de actualização periódica com dados contemporâneos ${ }^{(19)}$. Assim, o primeiro situar-se-ia ainda no século XIX/XVIII a.C., compreendendo os reinados de Šamši-Adad I e de seu filho, Išme-Dagan; a sua estrutura assentava numa divisão em três secções referentes aos antigos reis e uma quarta, a principal, onde já estava incluído o recém-chegado estrangeiro (amorita) ao trono assírio: Šamši-Adad I. Esta tradição não teve continuidade depois da queda da dinastia de Šamši-Adad I. Um segundo momento, situado nos séculos XVI-XV, abrangendo os reinados de Aššur-nērārī I e Enlil-nāșir I. Uma revisão e "edição alargada" consubstanciava, de acordo com o autor, o desenvolvimento da dinastia de Bēlu-bāni que aqui nos aparece na continuidade dos antigos reis assírios. Esta "edição alargada", porém, é parca em dados relativos ao período que se seguiu ao reinado de Šamši-Adad I. O terceiro momento, entre os reinados de Arik-dēn-ili e de Tukulti-Ninurta I, coincidindo com o crescente poder militar e político assírios. Os "exemplares" mais recentes (SADS, Nassouhi e Khorsabad) corresponderiam ao período de actualização periódica.

Que intenções/finalidades presidiram à elaboração das listas de reis, na Assíria? Os académicos têm apontado várias explicações: um interesse mais genuíno na cronologia/história real (visível no espaço mesopotâmico - Lista de Reis Suméria, Lista de Reis de Larsa, Lista de Reis de Ur-Isin), uma motivação política, e ainda a utilização como "amuleto" para benção da família real são hipóteses plausíveis.

A listagem sequencial de nomes de governantes, sejam chefes de tribos, sejam monarcas de entidades políticas mais estruturadas e complexas, proporciona uma visão unificadora de uma realidade política, conferindo-Ihe uma consistência e um sentido histórico de continuidade. Assim, o poder instituído reclama-se naturalmente legítimo. A identificação natural do soberano (ascendência histórica) expressa 
nas listas de reis pode permitir uma leitura despida de «intencionalidade ideológica", mais "positivista" num quadro de história política. São textos cronográficos nos quais o substracto ideológico e cultural praticamente desaparece. Porém, as listas de reis não devem ser tomadas como testemunhos desapaixonados do contexto que as produziu. $\mathrm{O}$ seu "positivismo factológico" não estará separado da vontade/momento político que esteve na sua origem ${ }^{(20)}$. Por outro lado, a perenidade de um texto, com o qual um modelo político e uma sociedade se identificam, pode conduzir a um valor simbólico, ser apropriado pelo todo social como "objecto virtuoso", gerador de "bênçãos".

As listas de reis assírias parecem ter obedecido a todos estes "papéis» e acompanhado a história do país de Aššur - a continuidade, mais ou menos ilusória que nos transmitem, revela, afinal, o apogeu e os momentos "apagados" ou menos brilhantes da Assíria. Redefinir hoje a cronografia da "Lista de Reis" assíria significa reconfigurar uma história política, ou seja, reencontrar o modelo do percurso histórico assírio.

\section{Tiglat-pileser I, o "país do Hatti» e o Mediterrâneo}

No ano subsequente ao da subida ao trono, Tiglat-pileser I (CC. c.1114-1076 a. C.) alude à sua incursão militar sobre as terras de Šubaru, às quais impôs tributo anual (vassalagem), e ao confronto com «4000 Kasku (e) Urumu, insubmissas tropas do Hatti - que tinham tomado pela força as cidades do país de Šubaru, que são vassalas do deus Aššur, meu senhor (...)”(21). No ano seguinte, a mesma fonte historiográfica refere o sucesso militar sobre "os rebeldes e insubmissos países de Isua (e) Daria" com imposição de vassalagem ${ }^{(22)}$. Isua (= Isuwa/Išua), situada na nascente do Tigre, faz parte do espaço hitita. O Hatti volta a ser mencionado em duas inscrições reais posteriores, cujos epónimos parecem ser sequências ${ }^{(23)}$ : 1) a quando do regresso da campanha militar sobre o país de Amurru e costa mediterrânea (Biblos, Sidon, Arvad), c. 1100 a. C.; o registo historiográfico menciona três incursões sobre as terras de Nairi já realizadas pelo soberano assírio, anteriores à expedição mediterrânea e, posteriomente, a perseguição aos ahlamû-Arameus até ao país do do Hatti. Afirma-se, ainda, que Tiglat-pileser I se tornou senhor de todo o país do Hatti, impondo a Ini-Tešub (rei do Hatti) tributos e impostos ${ }^{(24)}$; 2) incursão militar sobre Milidia do "grande país do Hatti», pagamento 
de tributo pelo rei Allumaru, conquista da "cidade de Enzatu do país de Išua e o país Suhmu», menção de prisioneiros e deportação para a Assíria ${ }^{(25)}$.

A avaliar pelo registo analístico, poder-se-á concluir por um estado de guerra assiro-hitita levado a cabo em dois momentos distintos: o primeiro, nos anos iniciais de reinado (c. 1113 a. C) e o segundo por volta do $15 . \% 16 .^{\circ}$ anos de reinado (c. 1100/1099 a. C.). Este estado de hostilidade consusbstanciaria o confronto com os reinos neo-hititas aos quais faltava uma unidade cultural e política. De facto, o império hitita havia já sucumbido, quase um século atrás, perante as investidas dos Povos do Mar, e o "país do Hatti" que as fontes assírias assinalam só aparentemente podia constituir uma entidade política, perdurando, todavia, na memória dos povos vizinhos. Este é o quadro convencional que configura o tempo de Tiglat-pileser I e a interpretação subjacente às suas campanhas militares por território do Hatti e costa mediterrânea.

Porém, e de acordo com a proposta de P. J. Furlong, Tiglat-pileser I terá reinado entre 1031-992 a. C. ${ }^{(26)}$ Para a análise e interpretação das campanhas militares dirigidas para o "país do Hatti" e para a costa mediterrânea, registadas nas inscrições deste soberano, o autor citado confrontou a informação analística com documentos que, mercê da nova cronologia proposta, foram considerados coevos do rei assírio. Assim, Tiglat-pileser I terá sido contemporâneo dos reis hititas Tudhaliya IV (CA c. 1056-1015 a. C.), Arnuwanda III (CA c. 1014 a. C.), Šuppiluliuma II (CA c. 1013 a. C.).

Para o primeiro momento (CC c. 1113 a. C. / CA c. 1030 a. C.) do conflito assiro hitita, Furlong considerou quatro documentos, para além da analística de Tiglat-pileser I, a saber: RS 34.165, Kbo IV 14, IBoT I 34 e Kbo XXVIII $65^{(27)}$, os quais, com o reposicionamento cronológico alternativo, são comtemporâneos do soberano assírio em causa. O primeiro, escrito em acádico, é uma carta de um rei assírio dirigida a um rei de Ugarit. O seu estado de conservação não permite identificar tais soberanos, mas, para o rei de Ugarit tem reunido consenso, entre os académicos, o nome de Ibiranu, filho de Ammistamru II e para o rei assírio, o nome de Salmanassar I (c. 12741245 a. C.) ou Tukulti-Ninurta I (c. 1244-1208 a. C.) ${ }^{(28)}$, de acordo com a cronologia convencional. Parte da informação nele contida diz respeito às relações entre a Assíria e o Hatti, dando conta que Tudhaliya [IV] (CC c. $1265-1235$ a. C.), rei do Hatti, declarara guerra ao país de Aššur, acusando o soberano assírio de conquista e captura de mercadores 
de um país aliado (vassalo?) do rei hitita. Em resposta, o rei assírio, enviara-Ihe a seguinte mensagem:

«Porque te pões em marcha contra mim? Saí eu contra ti?? Nesta altura reuni os meus soldados e os meus carros de guerra. Mas antes de eu tomar a cidade de Taidu, Tudhaliya, rei hitita, enviou outro mensageiro para mim trazendo duas tabuinhas hostis e uma amigável. Ele mostrou-me as duas tabuinhas hostis. Quando o meu exército ouviu as palavras hostis ficou impaciente e quis pôr-se em marcha; o mensageiro do rei do Hatti observou (isto). Decorridos três dias, o mensageiro do rei do Hatti apresentou-me a tabuinha amigável e sobre a tabuinha foi isto registado nestes termos. “(...) Eu juro que não sou hostil ao rei de Aššur, meu irmão, [mas] sou amigo. Eu juro que farei voltar para ele os fugitivos [....] os soldados [...] que fugiram do rei de Aššur e entraram no país do Hatti [...] Porque deveríamos nós, irmãos, estar em guerra um com o outro?».

Depreende-se daqui que as relações entre a Assíria e o Hatti, subjacentes ao documento, prefiguram um clima de hostilidade aparentemente contida, ou seja, o soberano hitita utiliza uma linguagem diplomática (o tratamento fraternal); por outro lado, o monarca assírio tomava a iniciativa de conquista de países reclamados por Tudhaliya IV como aliados, ou vassalos, do "país do Hatti». Todavia, o seguimento do discurso vai configurar a iminência da guerra: o documento (Rev. II. 1-39) parece indicar que, entretanto, o rei assírio cercara a cidade de Nihriya onde estavam posicionadas as tropas hititas e solicita ao rei do Hatti, numa tentativa mais diplomática, que retire as suas hostes e envie uma mensagem; este, porém, não envia qualquer mensagem, não retira as suas tropas e mostra-se decidido a marchar para o campo de batalha; é o rei assírio quem ordena o levantamento das suas tropas e se desloca para a cidade de Šura (actual Savur, situada a nordeste de Tur- (c) Abdin = Monte Kašiari), quiçá por razões estratégicas, tendo sido informado da decisão de Tudhaliya IV por um soldado hitita que fugira. A carta termina com o registo da derrota militar das tropas hititas, ou seja, a grande vitória assíria sobre Tudhaliya IV. De tudo isto é dada, através da carta, informação ao rei de Ugarit.

O segundo documento, KBolV 14, encontrado na capital hitita e escrito em caracteres cuneiformes hititas, menciona a cidade de Nihriya num contexto de confronto militar entre a Assíria e o Hatti. Consiste num tratado entre um rei hitita (não identificado) e um "sócio", também não identificado, no qual o monarca o acusa de "pecado", isto é, a falta de apoio no conflito que o opôs ao seu inimigo 
"O Homem de Aššur» e do qual saiu derrotado, tendo de retirar-se sozinho da cidade de Nihriya, fugindo para a cidade de Alatarma. Como consequência desta derrota perdeu as terras hurritas para a Assíria. De acordo com o documento, este "sócio" estava ligado ao rei hitita através de um juramento, devendo morrer por traição ao rei. É provável que se tratasse de um vassalo do soberano hitita. Pela cronologia convencional, esta ocorrência histórica enquadra-se no tempo de Tukulti-Ninurta I (c. 1244-1208 a.C.) e no período de fraqueza política e bélica subsquente ao assassinato deste soberano assírio(29).

Do terceiro documento, IBOT I 34, uma carta de um rei de Hanigalbat dirigida a um soberano hitita utilizando um tratamento filial (títulos/tratamento diplomáticos), ou seja, talvez indiciando uma relação de vassalidade, infere-se a hostilidade com a Assíria e o abandono forçado da sua capital dirigindo-se para a cidade de Šinamu (na região do monte Kašiari) a fim de evitar o encontro com o rei assírio. A carta menciona ainda Halpa-ziti, rei de Alepo e Ehli-šarruma, rei de Išuwa. Este documento, escrito em acádico e encontrado em Bogazköy, tem sido datado para o século XIII a. C., e Salmanassar I da Assíria identificado como o inimigo do rei de Hanigalbat referido na carta ${ }^{(30)}$.

Por fim, o quarto e último documento, KBo XXVIII 65, contemporâneo da carta acima indicada (IBOT I 34) e também escrito em acádico, menciona "rei de Hanigalbat» para "Sol... meu pai» e a cidade de Taidu na linha 5, adivinhando-se uma subordinação do rei de Hanigalbat face a um soberano hitita.

Considerando a hipótese cronológica de Furlong, a informação contida nestes documentos consubstancia a superioridade militar assíria na região a norte do país de Aššur, cuja envolvência geográfica é marcada pelo monte Kašiari, Hanigalbat ${ }^{(31)}$ e a cidade de Išuwa em território hitita, resultante da política belicista de Tiglat-pileser I assinalada nas inscrições reais. De facto, no ano de subida ao trono, a analística regista uma campanha militar em direcção às regiões montanhosas a sudoeste do lago Van, compreendendo os povos designados por Muški nas fontes assírias. Este percurso obrigava à passagem pelo monte Kašiari e Hanigalbat ${ }^{(32)}$; tal situação justifica, na perspectiva de Furlong, o conteúdo do documento IBO / 34 - a deslocação do rei de Hanigalbat para a cidade de Šinamu, abandonando, portanto, a capital, de forma a evitar o encontro com o rei assírio; paralelamente, contextualiza $R S 34.165$, II. 12-30a: “(..) Tudhaliya, rei do Hatti, escreveu o seguinte para mim, dizendo: "Porque conquistaste e capturaste os mercadores (?) do meu aliado? Vem, vamos 
lutar! (...) Eu marcho contra ti para a batalha" ». A guerra descrita em RS 34.165, Rev. II. 1-39, com a vitória declarada do soberano assírio, a aparente não resistência do vassalo hitita ("sócio" KBolV 14) e a fuga solitária do rei hitita da cidade de Nihriya (de acordo com Kbo IV 14), poderá acomodar-se ao discurso de vitória sobre o inimigo reclamada por Tiglat-pileser I: «4,000 Kasku (e) Urumu, insubmissas tropas do Hatti (...) O esplendor da minha coragem cobriu-os e, temendo a batalha, eles submteram-se-me»(33).

O segundo momento bélico assiro-hitita, após algum tempo de "paz" assaz longo (cerca de dezasseis anos), explicar-se-á pelo "turbilhão político" que naturalmente acontecia a seguir à morte de um grande rei do Hatti. De facto, após Tudhaliya IV (CA c. 1056-1015 a. C.), o seu sucessor Arnuwanda III, soberano por tempo breve (CA C. 1014 a. C.), foi deposto e assassinado na sequência de uma revolta interna, justificada (na perspectiva de Furlong) pelas vitórias arrasadoras de Tiglat-pileser I sobre a região síria com a sujeição de Karkemiš e dos seus territórios.

Documentação proveniente dos arquivos de Ugarit e de Boghazköy ${ }^{(34)}$, mal grado o seu estado de conservação, indicia uma situação de crise quer em Ugarit quer no Hatti, também evidenciada por material arqueológico ${ }^{(35)}$. Esta situação tem sido interpretada como prova do caos político característico do Bronze Final (CC c. 1200 a. C. / CA c. 1000 a. C.) resultante das investidas dos Povos do Mar e de outras coligações de natureza tribal. Todavia, Furlong propõe hipóteses explicativas que combinam estes dados com a informação que releva das inscrições reais de Tiglat-pileser I. Após a campanha militar deste soberano sobre o estado de Amurru e a sujeição das cidades de Biblos, Sídon e Arvad, Tiglat-pileser I prosseguiu para norte e tornou-se "senhor de todo o Hatti» (RIMA 2, A.0.87.3:16-28). Sendo governador de Mukiš (região situada a norte de Ugarit e na direcção de Karkemiš) um hitita, vassalo do rei de Karkemiš, e a região situada entre o limite sul de Ugarit e o reino de Amurru directamente governada pelo rei de Karkemiš, Tiglat-pileser I terá preferido voltar para Samuru (ilha em frente a Arvad), donde preparará o seu regresso para Kadeš e subirá o vale do Orontes até Mukiš (na região do monte Amanus), evitando o confronto previsível na região costeira entre Arvad e Ugarit. Terá sido em Mukiš que a coligação Hatti-Ugarit se encontrou com as tropas de Tiglat-pileser I, cujo resultado se traduziu na fuga, em pânico, do rei hitita, abrindo caminho para uma "senhoria" sobre "todo o estado do Hatti", referida nas fontes assírias (RIMA 2, A.0.87.3:26-28) e sustentada por material arqueológico ${ }^{(36)}$. 
Para fundamentar esta hipótese cronológica (reinado de Tiglat-pileser I), Furlong analisou ainda outras fontes textuais: KBo XII 39; RS 17 226; RS 17355 e RS 20216 O primeiro documento refere-se a um tratado hitito-cipriota (Alashiya $=$ Chipre ${ }^{(37)}$ ), o qual menciona um rei assírio "que nunca atravessou o mar, que nunca passou a entrada de Alashia". Esta fonte tem sido atribuída pela cronologia convencional aos reinados de Tudhaliya IV ou Arnuwanda III ou Šuppiluliuma II, logo, contemporânea do rei assírio Tukulti-Ninurta I, do qual, por sua vez, não há qualquer registo historiográfico que evoque a sua presença no Mediterrâneo. Tal incongruência favorece a hipótese proposta por Furlong, pois, estabelecendo uma cronologia paralela entre os reis hititas mencionados e Tiglat-pileser I, o autor enquadra a fonte textual nas actividades militares na costa mediterrânea levadas a cabo por este rei assírio. De facto, Tiglat-pileser I não chegou a Chipre, mas a sua presença em Arvad, a $60 \mathrm{~km}$ a sul de Ugarit e a $100 \mathrm{~km}$ de Alashiya, daria credibilidade a uma hipótese bastante razoável de 0 poder vir a concretizar. Outra documentação(38) ${ }^{(3)}$. ração de forças/relações de poder envolvendo Ugarit, Karkemiš e o Hatti. Um tratado firmado entre Šuppiluliuma II (Hatti) e Talmi-Tešub (Karkemiš), no qual os dois soberanos são referidos com igual estatuto político e onde o segundo aparece como mediador do divórcio de Ammurapi (rei de Ugarit) e Elhi-Nikkalu, filha do grande rei hitita ( $R S$ 17 226, RS 17355 e RS 20 216). Tal divórcio, sem precedentes na história hitita, revela algo surpreendente: sendo Ammurapi vassalo do grande rei hitita, estranha-se que rejeite, e sem invocação de motivo, a filha do monarca seu suserano. Ainda numa carta (RS 20 212), provavelmente escrita pelo rei de Karkemiš, como intermediário entre os soberanos do Hatti e de Ugarit, evidencia-se a desobrigação de compromissos entre estes últimos.

De toda esta documentação, inferiu Furlong a afirmação política de Tiglat-pileser I em território sírio, cuja suserania pertencera ao grande rei do Hatti e justificar assim a fraqueza de Šuppiluliuma II (visível no divórcio de sua filha) e, ainda, um possível tratado comercial assírio com o país de Amurru. Neste xadrez político, Karkemiš parece ter permanecido fiel ao Hatti, quiçá pela natureza familiar das suas relações dinásticas. Com efeito, o poder real instalado em Karkemiš era um sub-ramo da dinastia do Hatti e tais ligações familiares poderão ter sido suficientemente fortes para resistir à pressão assíria.

Das guerras assiro-hititas, ressalta, naturamente, uma questão: porque razão Tiglat-pileser I não menciona nas suas inscrições o 
nome de Tudhaliya IV, mas assinala apenas a sua vitória sobre as tropas hititas (RIMA 2, A.0.87.1: ii89-iii6), inscrita no primeiro momento dos confrontos assiro-hititas. O próprio Tudhaliya IV admitiu a derrota às mãos de um rei assírio ( $K B O I V$ 14). Tiglat-pileser I registou a sua dupla vitória sobre o rei babilónico, Marduk-nadin-ahhé (RIMA 2, A.0.87.4: 44-51), porém, não o fez em relação ao rei hitita. Parece, no entanto, ter informado Ibiranu, rei de Ugarit (RS 34 165, ver acima primeiro confronto assiro-hitita, segundo a perspectiva de Furlong) da sua vitória sobre Tudhaliya IV.

Nos confrontos militares de Tiglat-pileser I com o Hatti, registados na analística (RIMA 2, A.O.87.1. v 33-41), a cidade de Malatya/ /Milidia aparece como sendo do país de Hanigalbat, o que tem sido apontado como erro do escriba, pois pertenceria ao Grande Hatti como, aliás, vem posteriormente referida noutra fonte historiográfica (RIMA 2, A.0.87. 3. 31-33). Esta incorrecção cronística teve, contudo, outra leitura na tese de Furlong. A cidade de Malatya/Milidia terá sido conquistada, pela primeira vez, por Salmanassar I (CC c. 1274-1245 a. C., CA c. 1189-1160 a. C.) no decurso da sua campanha sobre o estado de Hanigalbat (RIMA 1, A.0.77.1:47-53) e objecto de disputa legal entre o rei assírio e o rei hitita seu contemporâneo ${ }^{(39)}$. De facto, em termos geográficos, Milidia situa-se na região de fronteira entre o estado mitaniano (Hanigalbat) e o Grande Hatti. Assim, quando Tiglat- plieser I conquistou os estados hurritas, nos primeiros anos do seu reinado e refere Milidia enquanto cidade do estado de Hanigalbat (RIMA 2, A.0.87.1. v 33-41), poderá não ser um erro do escriba, mas antes, uma estratégia política, um "gesto conciliatório", para manter boas relações com o Hatti. Não tendo Tiglat-pileser I tomado uma cidade hitita, mas antes mitaniana, Tudhaliya IV não poderia alimentar razões para hostilidades militares contra a Assíria ou para boicotar as relações comerciais entre o país de Aššur e o ocidente, evitando, deste modo, uma invasão sobre a região síria, por parte de Tiglat-pileser I, e 0 acesso directo assírio aos portos mediterrâneos ${ }^{(40)}$. $O$ enquadramento político do segundo confronto assiro-hitita, porém, configura um cenário assaz diverso do primeiro: a Assíria assumia-se já como a grande potência político-militar da região, dispensando alianças ou "amizades" hititas para obter os seus propósitos comerciais. Com efeito, a referência à cidade de Milidia (pela segunda vez) na fonte assíria (RIMA 2, A.O.87.4: 31), situa-a no "grande estado do Hatti», ou seja, inscrita na província hitita de Tegarama e governada directamente pelo rei do Grande Hatti. 


\section{Conclusões}

1. As novas propostas conológicas permitem "resolver" o denominado "período obscuro" (Dark Ages) do Bronze Tardio, ou seja, eliminar um tempo do qual pouco ou nada se sabe por via da ausência de provas textuais ou outras. Esta reavaliação cronológica induz, naturalmente, ao repensar do modelo político do período médio assírio e ao enquadramento histórico do colapso final do estado imperial hitita, bem como, particularmente, à articulação entre Bronze Tardio e 1. ${ }^{a}$ Idade do Ferro em contexto assírio.

2. A actividade militar e política de Tiglat-pileser I no tocante ao espaço siro-hitita ganha consistência e configura uma co-responsabilidade pelo desaparecimento do Hatti enquanto unidade política imperial. Com efeito, Tudhaliya IV, Arnuwanda III e Šuppiluliuma II, contemporâneos de Tiglat-pileser I, confrontam-se e saem derrotados dos seus encontros com o rei assírio. $O$ quadro de hostilidade aberta e de guerra efectiva, entre a Assíria e o Hatti, é ainda entre dois estados soberanos de cariz imperial e redimensiona a geo-estratégia política assíria.

3. O domínio assírio na costa mediterrânea ocidental (Biblos, Sídon, Arvad, Ugarit) teve implicações económicas num contexto mediterrâneo que poderá ter incluído, não apenas Chipre, mas também Micenas.

4. O reposicionamento cronológico do reinado de Tiglat-pileser I coloca-o mais próximo do período neo-assírio, situação que se ajusta ao enriquecimento da imagem do soberano e ao conteúdo simbólico do poder inscrito no discurso historiográfico das inscrições reais ${ }^{(41)}$.

\section{Notas}

(1) P. JAMES et al., Centuries of Darkness - A Challenge to the Conventional Chronology of Old World Archaeology, London, 1991.

(2) http://www.newchronology.org/cgi-bin/open.cgi?page=index2 (activo em Agosto 2009).

(3) High, Middle or Low? International Colloquium on Absolute Chronology Held at the University of Gottenburg, 20-22 August, 1987, Gottenburg.

(4) BASOR 278 (May, 1990), New Haven/London.

(5) J. A. BRINKMAN, "Comments on the Nassouhi Kinglist and the Assyrian Kinglist Tradition», Or 42, 1973, 306-319. 
(6) N. POSTGATE, "The Chronology of Assyrian Insurmountable Obstacle», Cambridge Archaeological Journal 1, 1991, 227-253. Cf. B. NEWGROSH, "The Chronology of Ancient Assyria - Re-assessed", JACF 8, 1999, 78-88.

(7) P. J. FURLONG, A Contribution to Ancient Near Eastern Chronology (c. 1600-900 BC), Melbourne, 2007. Disponivel em The University of Melbourne e-Prints Repository: http:// eprints.infodiv.unimelb.edu.au/archive/00003929/ (activo em Agosto 2009).

(8) B. NEWGROSH, "Part 2 Reconstructing the King List", JACF 8, 1999, 89-106; "The Chronology of Ancient Assyria - Re-assessed An Update", JACF 9, 2002, 109-112.

(9) P. JAMES, Century of Darkness - A Challenge to the Conventional Chronology of Old World Archaeology, London, 1991, 299.

(10) Aššur-dan I poderá ter governado 36 anos depois de 10 em co-regência com o seu pai.

(11) Utilizar-se-ão as siglas CC e CA para cronologia convencional e cronologia alternativa, respectivamente.

(12) 1. "Nassouhi List" (= Aššur A, E. WEIDNER, AfO 4, 1927, 1-11 e pls. 1f); 2. "Khorsabad List" (I. J. GELB, JNES 13, 1954, 209-230 e pls. 14 f.); 3. "SDAS List" (ibidem, pls. 16 f.), c. 935 a.C.; 4. KAV 1, 15, E EBELING (= Aššur B), A. K. GRAYSON RIA 6, 1980, 101-115; 5. BM 128059, proveniente de Nínive, A. MILLARD, Iraq 32, 1970, 174-176.

(13) J. A. BRINKMAN, "Comments on the Nassouhi Kinglist and the Assyrian Kinglist Tradition», Or 42, 1973, 306-319. Ver também G. HAGENS, "The Chronology of Tenth-Century Assyria and Babylonia", JACF 9, 2002, 61-69.

(14) J. A. BRINKMAN, "Comments ...", 310: Puzur-Aššur III (no.61): 24 anos (SDAS ii. 29)/ 14 anos (NaKL ii 35); Aššur-nādin-apli (no.79): 4 anos (NaKL iii 31)/ 3 anos (KhKL iii 22, SDAS iii 12); Ninurta-apil-Ekur (no.82); 13 anos (NaKL iii 40), 3 anos (KhKL iii 30; SDAS iii 17); Tiglath-pileser II (no.97): 33 anos (KAV 22 v 9", referindo-se ao período do epónimo), 32 years (KhKL, iv 13), in Brinkman, 311.

(15) J. A. BRINKMAN, "Comments...", 311: Aššur-nirāri II (no. 68): filho de Enlil-nāṢir (I/II; KhKL, iii 3), filho de Aššur-rabi I de acordo com uma inscrição do seu próprio filho, Aššur-rā'im-nišēšu (KAH 1 63:3-4, cf. KAH 2 25:8-9); Aššur-rā'im (rē'im)-nišěšu (no.70): filho de Aššur-bēl-nišěšu (KhKL iii7, cf. NaKL, iii 11), filho de Aššur-nīrāri II de acordo com o seu texto (KAH 1 63:3); Eriba-Adad I (no.72): filho de Aššur-bēl-nišěšu (KhKL iii 11, SDAS iii 4, talvez sustentado por KAH 2 25), filho de Aššur rā'im-nišēšu (NaKL iii 15); Adad-nīrāri I (no 76): filho de de Arik-dēn-ili (NaKL iii 23 e a sua inscrição real, KAH 1 7:2, 8:2, 9:2...), irmão de Arik-dēn-ili (KhKL iii 17, SDAS iii 8); Aššur-nīrāri III (no. 80): filho de Aššur-nașir-apli (NaKL, III 23, SDAS iii 13), filho de Aššur-nâdin-apli (NaKL iii 32); Eríba-Adad II (no.90): filho de Aššur-bēl-kala (NaKL iv 12.16, SDAS iii 31.35, KhKL, iii 45), filho de [llukabk]abi (KhKL iv 2-3); Tiglath-pileser III (no.108): filho d Adad-nīrãri III (KAH 1 21:2), filho de Aššur-nīrāi V (SDAS iv 24).

(16) Aššur-nādin-apli é o rei no. 79 em NaKL iii 30 e em KhKI iii 21, mas Aššur-nâșir-apli em SDAS iii 11.

(17) Salmanassar II (rei no. 93) é omisso em NaKL.

(18) J. J. GLASSNER, Chroniques mésopotamiennes, 146.

(19) S. YAMADA, "The Editorial History of the Assyrian King List", ZA 84, 1994, 11-37.

(20) Sobre esta questão ver particularmente M. van de MIEROOP, Cuneiform Texts and the Writing of History, London/New York, 2006, esp. 47. 
(21) A. K. GRAYSON, The Royal Inscriptions of Mesopotamia. Assyrian Periods 2 (= RIMA 2), Toronto, 1991, A.O. 87.1, ii 89-iii 6.

(22) Ibidem iii 88-91.

(23) C. SAPORETTI, Gli Eponimi medio-assiri (= GEMA), Malibu, 1979, 161-2.

(24) A. K. GRAYSON, ibidem, A.O. 87.3, II. 26-30.

(25) Ibidem, A.O. 87.4, II. 31-33.

(26) Tiglat-pileser I, no quadro das novas propostas cronológicas, situa-se em: c. 1062-1024 a. C, in G. HAGENS, "The Chronology of Tenth-Century Assyria and Babylonia", JACF 9, 2002, 61-69; c. 1010-972, in P. JAMES et al., Centuries of Darkness, London, 1991; c. 985-957 in B. NEWGROSH, "The Chronology of Ancient Assyria Reassessed. An Update", JACF 8, 1999, 109-112. Este último autor reduz o reinado do soberano assírio em cerca de 10 anos, ou seja, terá apenas governado 29 anos.

(27) $R S=$ refere-se às tabuinhas de argila encontradas em Ras Shamra (Ugarit); Kbo = Keilscrifttext aus Boghazköy (tabuinhas de argila encontradas na antiga capital hitita Hattusa); IboT = H. G. Güterbock et al, Istanbul Arkeoloji Müzelerinde Bullunan Bogazköy Tbleterinden Seçme metinler, vol. I, Istanbul, 1944.S. Para a tradução que aqui se apresenta, ver S. LACKENBACHER, "Lettre du roi (d'Assyrie?) au roi (d'Ougarit?)", in P. Bordreuil (ed.), Une bibliothèque au sud de la ville, RSO VII, Paris 1991, 93-94. Ver também A. HARRAK, Assyria and Hanigalbat, Hildesheim/Zurich/New York, 1987, 140-142, 217-218, 77-79 e 79 .

(28) A. HARRAK, Assyria and Hanigalbat, 142; S. Lackenbacher, "Lettre du roi (d'Assyrie?) au roi (d'Ougarit?)", in P. Bordreuil (ed.), Une Bibliothèque au sud de la ville, RSO VII (1991), Paris, 155-156, I. Singer, "The Battle of Nirihya and the End of the Hitite Empire", ZA 75 (1985), 100-123.

(29) A. HARRAK, Assyria and Hanigalbat, 218.

(30) Para a identificação dos outros reis, ver bibliografia específica in A. HARRAK, Assyria and Hanigalbat, 78 , nota 36 .

(31) Hanigalbat corresponde à parte oriental do antigo estado hurrita/mitânio.

(32) A. K. GRAYSON, RIMA 2, A.0. 87.1 i $62-88$

(33) A. K. GRAYSON, RIMA 2, A.O. 87.1 ii 89- iii 6.

(34) Ugarit - RS 16.402 (=KTU 2.33), RS 16379 (= KTU 2.30), RS 18.40 (=KTU 2.40), RS 18.38 (= KTU 2.39) e 34.143 (= F. Malbran-Labat, "Lettres", in P. Bordreuil (ed.), Une bibliothèque au sud de la ville, RSO VII, Paris 1991, 27-29); Boghazköy - KTU 2.47 (=RS 18.148).

(35) P. FURLONG, Aspects of Ancient Near Eastern Chronology, 56.

(36) P. FURLONG, Aspects of Ancient Near Eastern Chronology, 56.

(37) P. FURLONG, Aspects of Ancient Near Eastern Chronology, 57, n. 109.

(38) H. KLENGEL, Syria 3000 to 300 B.C., Berlin, 1992, 127.

(39) A. HARRAK - 139, KBo XVIII 24.

(40) P. J. FURLONG - Aspects of Ancient Near Eastern Chronology, 62, n. 120.

(41) M.L. PALMA, Tiglat-pileser I e o seu tempo. A guerra, as leis e a ideologia. Contributos para a sua análise, Lisboa, 2003, 364-365 (texto policopiado, Ed. Colibri). 